\title{
european journal
}

\author{
of agricultural
}

education and

extension
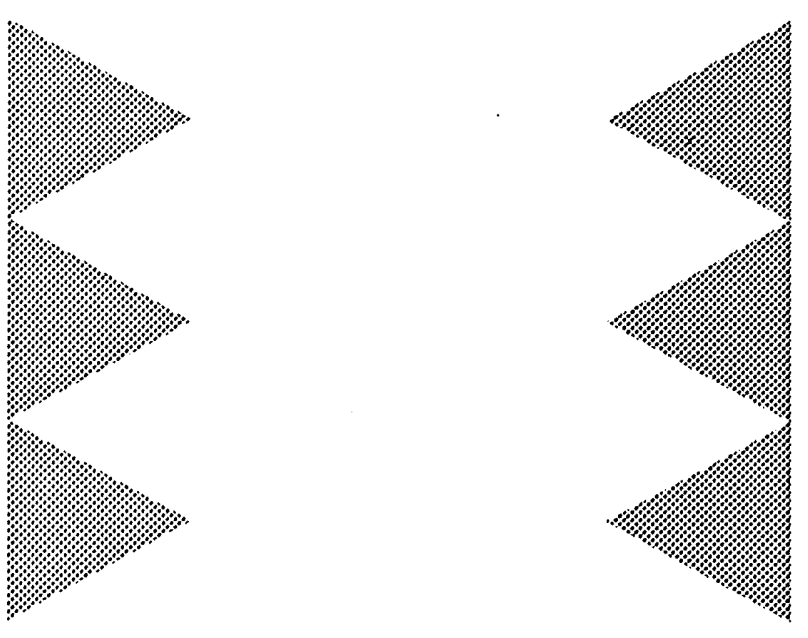

\section{international journal on changes in agricultural knowledge systems}

K.G. Eveleens and Current trends in post-graduate educaR. Rabbinge tion at the Wageningen Agricultural University: innovation, organisation and internationalization

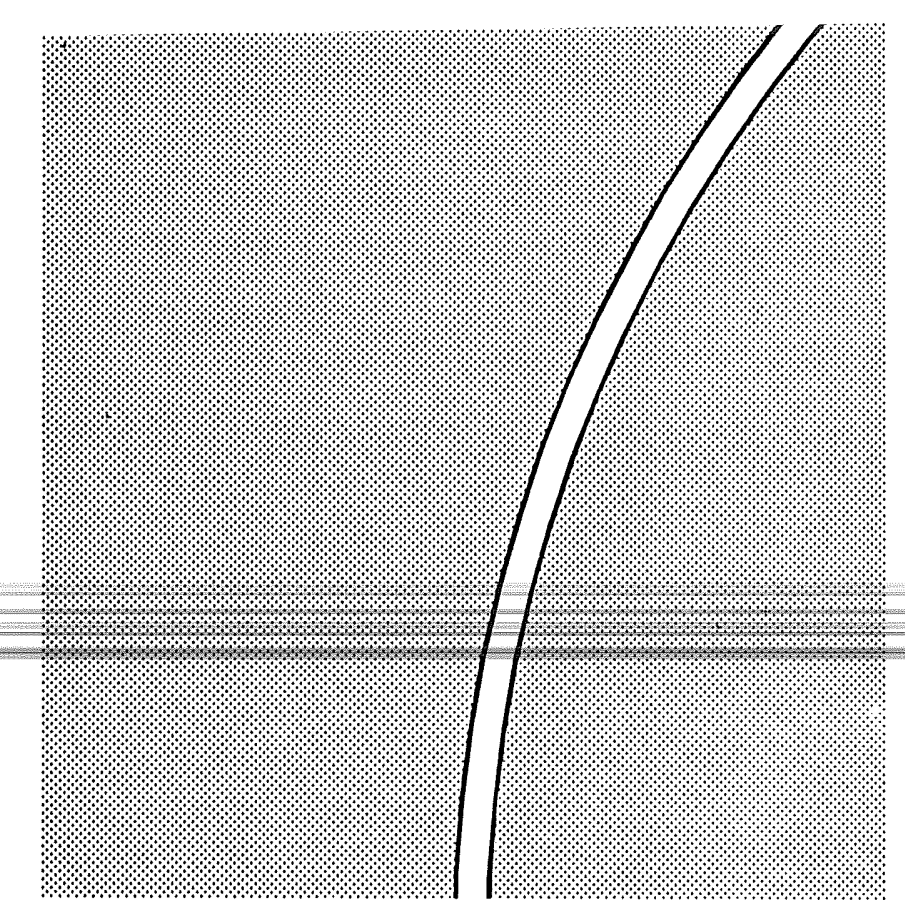


Current trends in post-graduate education at Wageningen Agricultural University: innovation, organization and internationalization.

\author{
R. Rabbinge* \\ K.G. Eveleens*
}

\begin{abstract}
The origin of agricultural knowledge innovation systems in the Netherlands goes back to the crisis situation in European agriculture of the late nineteenth century, which was met by putting a concerted effort in strengthening of competitive ability. The resulting close-knit evolution of the triad research/extension/training has largely determined the orientation of the present agricultural education and research system. Strengths and weaknesses of this system are listed and briefly discussed.

Post-graduate agricultural education in the Netherlands, concentrated at Wageningen Agricultural University, is in state of transition in the two following, inter-related aspects:

1. Internationalization. After many generations of Wageningen graduates have experienced the benefit of an international element in their training through a practical period abroad, organizational adjustments to a more comprehensive, 'two-way' internationalization (i.e., also providing access to foreign students) are now underway.

2. Structuring a post-graduate curriculum. Important in this context are the recent institutionalization of research activities in areas of acknowledged strength into a number of 'Centres of Excellence' (onderzoekscholen) and initial moves towards establishment of graduate schools.
\end{abstract}

- Department of Theoretical Production Ecology, Wageningen Agricultural University, The Netherlands 
Introduction: History of agriculture in the Netherlands and the role of knowledge innovation.

Agricultural research and post-graduate education in the Netherlands evolved in close interaction with historical developments in agriculture. Therefore, we first present a brief overview of those historical elements which have been instrumental in shaping our present system of higher education in agriculture.

The agricultural crisis late in the last century that took place in Europe, partly due to the import of cheap wheat from the new world (United States of America) with steamboats instead of sailing boats, caused a different reaction of different governments. The German authorities, heavily depending on the feudal structure in that country, propagated closure of frontiers. And so did France. The English government liberalized, and was able to do so as there was a strong pull for labour from the growing industrial sector. Farmers went bankrupt and farm size and structure were adapted, enabling competition with the new world. The Dutch and probably also the Danish were too dependent on international markets to close their frontiers (Holland had already been for ages a trade nation). At the same time, however, both countries were facing the dilemma that liberalization would cause big problems as more than $50 \%$ of the population was working in agriculture and alternatives were at that time absent.

Therefore, strengthening of the competitive ability was advised by a state advisory body headed by the renowned liberal leader Thorbecke. It recommended (1), improvement of the infrastructure (land reclamation, adapting farm structure etc.), (2), enhancement of farmers' participation in marketing (farmers cooperations, market organisation structures etc.) and, last but not least (3), strengthening of a knowledge innovation system. Extension services, agricultural education and research were started or stimulated. At that time a school for higher agricultural training had already been established in Wageningen. Somewhat later (1918) this school attained the status of agricultural university. 
Reactions to subsequent crisis situations in agriculture have followed about the same patterns in the various countries. This was clear in the thirties and fifties of this century. The British liberalizing, the Germans and French promoting protection, and the Dutch and Danish governments promoting competitive ability. At present the discussions in the European Union (EU) on restructuring of the Common Agricultural Policy show the same type of debate with the same positions. Not surprisingly, this is also the debate in the General Agreement on Tariffs and Trade (GATT).

As a result of this long tradition of emphasis on competitive ability, Dutch agriculture has a very powerful position in high technical agriculture (horticulture, dairy, seed potatoes, seeds etc.). The export value is very high (3rd of the world), the balance of trade in agricultural products is positive and the contribution of products that are affected by the EU market policies is relatively small in comparison with other EU countries. With these products the Netherlands is leader of the market. However, changes in agriculture due to technological change, shifts in markets outside and within the EU, and the increasing importance of other objectives than the traditional drive for higher production (environmental, nature conservation and landscape, maintenance of employment in agriculture) affect agriculture and its environment. For the Netherlands and other European countries the EU-policy sets the scene for any development in rural areas. In this context, mention should be made of a study on options for use of rural areas in the EU (Rabbinge and van Latesteijn, 1992). Modern techniques of simulation and systems management, incorporating both technical information and policy views as input data, were used to generate different land use scenarios in accordance with prevailing political considerations. The subject matter of such a study is of interest to both policy makers and research managers concerned with the common objective of development and application of eco-technological innovations leading to high productivity in conjunction with minimal environmental side-effects. This brings us to the significance of knowledge innovation systems, which will be discussed in the following section. 


\section{Knowledge innovation systems}

The capability to generate and utilize scientific and technological innovation is of vital importance to solve the problems facing our society. A conspicuous feature of agriculture in the Netherlands is that its innovation process, more than in other sectors of economic activity, proceeds in a very organized and structured system, provided by an effective integration of research, extension and training. The knowledge innovation system should thus be viewed holistically as a kind of pyramid in which primary education, vocational education, extension, university education and applied and basic research all are essential elements, ideally operating in a synergistic fashion.

The question whether the Dutch knowledge innovation system is meeting the requirements of a balanced pyramidal structure has been addressed in a recent survey on assets and liabilities of agriculture in relation to innovation, carried out by the Dutch Scientific Council for Government Policy. According to this study (Wetenschappelijke Raad voor het Regeringsbeleid, 1991), strong characteristics of the Dutch knowledge innovation system in agriculture are:

1. The high level of training of people working in agriculture.

2. A well-developed national cohesion as well as physical and institutional infrastructure. Concentration in a ministry of agriculture of responsibilities for the infrastructure, the economical aspects and the education system.

3. The direct influence of farmers and horticulturists and their organisations on extension and the adaptive and applied research. The efficiency- and efficacy attitude of the whole system to improve production and productivity.

4. Homogeneity regarding common objectives and norms among the various parties involved in agriculture. This is one of the major strengths for the whole field.

Some negative aspects, identified in the same study, are:

1. Other objectives than those which are production-oriented are neither sufficiently explicitized nor incorporated into research policies. 
2. Insufficient possibilities to pick up signals from the outside world, the system is too closed.

3. The way of financing research; too much input and too little output-financing.

4. Unclear division of tasks between the ministries of agriculture and of economical affairs, and between the ministries of agriculture and of science and education.

5. The decreasing interest in basic research. A reduction in the duration of university study and a too slow implementation of the envisaged structure of advanced education (the so-called second phase of academic training).

General awareness of some of these negative factors has led to criticism that agricultural policies in the Netherlands are geared too much to the interests of primary production, at the detriment of attention to aspects affecting society at large, such as environmental issues, ethical dimensions of genetic manipulation, and consequences of modern production methods for food quality and safety.

Here we move into problem areas which transcend mere technological considerations. Wageningen University should be alert to these trends and play an 'avant-garde' role in fomenting incorporation of such novel elements in the educational process. An illustrative example of the continuing need for adaptation of knowledge-innovation systems is provided by the impact on academic training and research by the officially endorsed long-term strategic plan for crop protection. This prescribes a phasing out of chemical pesticides, resulting in an increased exploration of alternative methods of pest control and concomitant re-orientation of research and education in crop protection.

It thus appears that the success of the knowledge innovation system depends on its cohesion, its completeness, its flexibility and its responsiveness to the environment. One of the principal components of this system is the post-graduate education and in the remainder of this paper we want to discuss some features of the post-graduate education at Wageningen University. 
Post-graduate education in the agricultural and environmental sciences

\section{Institutional framework}

Wageningen Agricultural University is unique in the sense that its 65 departments, covering a wide variety of different disciplinary fields of study which include Plant and Animal Sciences, Biosciences and Product Technology, Use of Land and Natural Resources, and Economic and Social Sciences, are all united in one faculty, the 'Faculty of Agricultural and Environmental Sciencer'. The added dimension 'Environment' reflects the need to consider agricultural practices in the comprehensive context of management of our total environment. This calls for strengthening of the interdisciplinary component in the university education. Particularly so at the post-graduate level, if we want our students to provide tomorrow's expertise as needed to develop agriculturally and environmentally sound production systems.

There is a clear need to increase understanding of the processes that cause inefficiencies and pollution and to harness the combined potential of technological improvement and behavioural changes of individuals and institutions to implement ecologically and economically acceptable production techniques. Of course, scientific training is just one element, but it is a vital one.

\section{Wide and deep}

The combination of basic and applied resarch is essential for the quality of training. Wageningen is a hybrid of a university (mainly deep) and an experimental station (mainly wide). The pursuit of academic excellence is heavily permeated with the flavour of application, but a qualitative and quantitative understanding of the processes underlying manipulation and guidance of production systems is essential. Therefore the role of basic sciences is vital and the bridge to application is laid by various interdisciplinary, 'supra-departmental' working groups. Experience has shown that tangible synergistic benefits accrue from such cooperation between various disciplines. 
Quality standards and collaboration with other institutes

In Wageningen, advanced agricultural scientific training is provided and an outward look is prerequisite for maintenance of standards of performance. The quality of academic training is increased by cooperation and exchange of students with universities within the Netherlands as well as, more importantly, in other countries. As Wageningen is the only place for academic education in agricultural and environmental sciences in the Netherlands, interaction with comparable institutions abroad is of crucial significance. Although there is now common awareness that the time of academic parochialism is definitely passed, translation of such consensus into organizational adjustments needed for effective internationalization remains problematic. This issue is addressed in the following section.

\section{Internationalization in agricultural education}

Already for a long time a practical period of work of half a year duration has been incorporated in the curriculum of all studies at Wageningen University and students are being encouraged to spend this period abroad. Internationalization, in this restricted sense of fostering international orientation in graduate training, has therefore traditionally been part and parcel of the education offered. However, true internationalization is a matter of two-way traffic and also requires effective opening of the university to foreign students. Initiation of steps into this direction are of a more recent date. As far as Europe is concerned, this is a logical development in view of the disappearance of the internal EU borders. But more students from other continents are being accommodated as well. This is mainly in the context of a number of Master of Science (MSc) programmes of 17 months duration, taught in English and catering to Bachelor of Science (BSc) holders in agriculture or biology from all over the world. The increase in this category of students over the last ten years, as compared to trends in numbers of new registrations of regular students, is indicated by the figures of Table 1 . 
Table 1 Numbers of newly registered students at Wageningen Agricultural University in the period 1983-'92

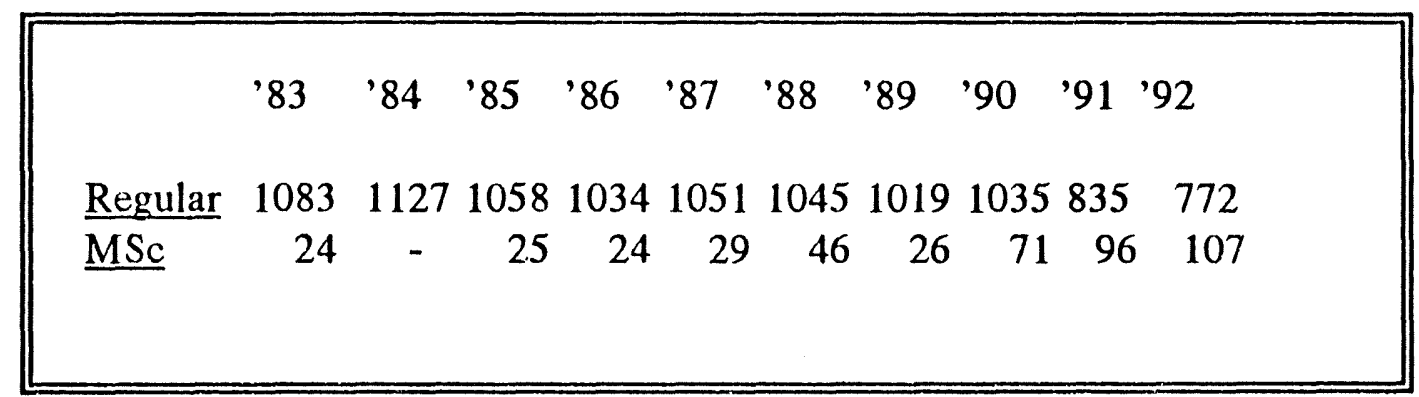

Source: Office of Student Affairs, Wageningen Agricultural University.

University authorities, facing the need of organizational adjustments to incorporate these MSc programmes in existing curricula, are still grappling with problems of trade-off between interests of internationalization on the one hand and preservation of national academic traditions, perceived as assets, on the other hand. An elementary first step in attuning international and regular study programmes is a clear delineation between 'pre-graduate' and 'post-graduate' study phases. This is important because most overseas students in Wageningen had their previous university education in the Anglo-American system or some derived version, where the 'Bachelor of Science' degree clearly marks the entrance into graduate studies. In the Dutch system there is no BSc degree. The first academic title given is 'Ingenieur' (Ir) and the general thinking in the Netherlands is that this is superior to a BSc. Awardance of the Ir degree represents, according to these opinions, more than just the conclusion of undergraduate education. It also purports to include advanced elements which would put the degree on a par with the Master of Science.

Unfortunately, many overseas educators seem not to agree with this assessment. In a recent survey on status assigned to the Dutch academic diplomas of 'doctorandus' and 'ingenieur' in England and the United States, Bolle (1991) found that in most cases these were considered equivalent to $\mathrm{BSc}$ rather than $\mathrm{MSc}$. Such discrepancy raises various 
problems for international academic coordination in agricultural education. Firstly, it tends to put graduates from Dutch universities at a disadvantage when they file applications abroad, be it for admission to post-graduate university studies or for employment. Conversely, for students from abroad entering Wageningen University, for example to participate in one of our international MSc programmes, it is sometimes difficult to determine the level at which they should join in because of this ambiguity on which constitutes the graduate phase of the study. To speak in agricultural terms, there is a compatibility problem in grafting the Anglo-American MSc-scion on the Dutch academic rootstock. A similar problem of adjustment to academic internationalization in Denmark was solved by institution of a formal Bachelor degree (Schmidt-Nielsen, 1992). At Wageningen University, present thinking goes in the same direction. A cautious first step was the institution of a so-called 'BSc certificate' which, however, does not yet have the status of a formal degree.

The need for clarity on the issue of academic titles is not only obvious with regard to international coordination, but has also acquired urgency in view of recent developments at the national level. A plan has been formulated to give the Wageningen Agricultural University the national mandate for academic quality control on a number of MSc courses given by various autonomous institutes. Acceptance of this plan will certainly lead to increased exploration of possibilities for joint offering of related curricular elements. In this context it is interesting to refer, again, to Denmark, where admission to an MSc programme 'Seed Pathology' of the Veterinary and Agricultural University of Copenhagen is contingent upon prior completion of the international course in this area given by the Danish Government Institute of Seed Pathology for Developing Countries (DGISP). In a similar effort to achieve much-needed pooling of resources, in teaching expertise as well as fellowship funds for overseas students, Wageningen Agricultural University has started collaboration with the International Agricultural Centre (Wageningen, the Netherlands) in joint offering of part of the lectures, excursions and practical exercises of respectively the University MSc Programme Crop Science, specialization Crop Breeding, and the IAC International Course in 
Applied Plant Breeding.

Nowadays, this issue of organizational adjustments, needed to meet the needs of increasing international engagement, tends to be more and more viewed in the entire context of current efforts to provide a better structured curriculum for advanced students in thesis-oriented studies leading to a post-graduate degree (MSc equivalent or $\mathrm{PhD}$ ). In the following, concluding section present status and some anticipated developments are briefly discussed.

\section{Towards a better structuring of post-graduate education}

Until recently advanced training only took place in more or less :aformally operating, loose networks of $\mathrm{PhD}$ students and their

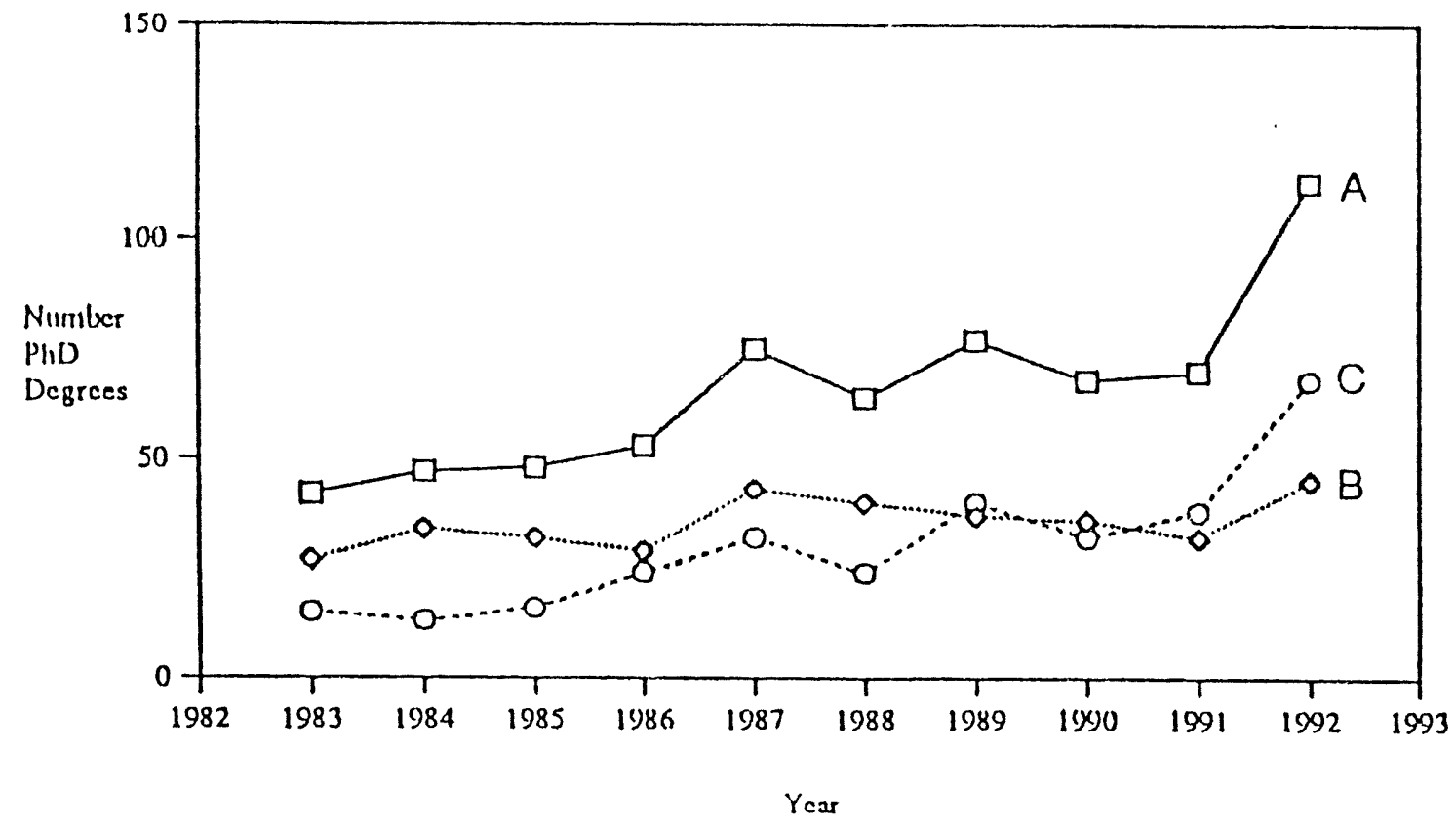

Fig. 1. Numbers of $\mathrm{PhD}$ d. grees awarded in relation te categoeries of funding (1983-'93). A: to'als: B: regular funding; C: funded by third parties (contract research ind external candidates)

Source: Office for Education and Science, Wageningen Agricultural University. 
supervisors. Impetus towards better structuring is being provided by the growing significance of the category of $\mathrm{PhD}$ students. This is reflected in Figure 1, which gives numbers of $\mathrm{PhD}$ degrees awarded over the last decade. There is a clear overall increase (graph A). The fact that this is more apparent in the category of $\mathrm{PhD}$ thesis research funded by third parties (graph C) than in the category of thesis research funded from the regular budget (graph B), is indicative of the competitive strength of $\mathrm{PhD}$ - level research at Wageningen. Extrapolating from current trends and considering required change, we may anticipate establishment, in the near future, of four or five formal graduate schools, corresponding to the subdivision of the Faculty in sectors. Following up on 'tertiary' training at the university undergraduate level, these graduate schools would provide the institutionalization of 'quaternary' education at the Master's and $\mathrm{PhD}$ level with the added benefit of facilitating international MSc graduates of proven ability to continue in a $\mathrm{PhD}$ programme.

Also the process, already initiated, of capitalizing on areas of outstanding research within the university by creation of so-called 'centres of excellence' (in Dutch 'onderzoekscholen') will result in improved opportunities of training for advanced students. Such 'centres of excellence' transcend traditional university boundaries to include expertise from other national agricultural research institutions as well. At present six centres of excellence have been established by Wageningen University: Experimental plant sciences; Production ecology; Environmental chemistry and toxicology; Food technology, nutrition and human health; Environment and climate studies. The Centre of experimental plant sciences, for example, aims at an intensification of detailed research at the subcellular level to understand the functioning of growth and development in plants and thus pave the way for application in plant breeding and crop protection. There is an intensive cooperation with other universities in this field. The Centre of production ecology aims at the integration of basic research on the one hand and its application on the other. At various levels of integration, from the cellular/individual level up to the level of land use systems, studies are done to develop concepts of sustainable land use and production systems that are ecologically sound and economically feasible. 
In summary, post-graduate education in Wageningen is still in a state of flux with respect to institutionalization within the national system as well as to developments relating to international integration. Resulting uncertainties, shifting priorities and organizational upheavals exasperate some staff for whom these winds of change are too strong fur comfort. But there is increasing awareness that standstill is, for better or for worse, more than ever equated with regression. And also that in a world where national boundaries become more and more immaterial to the essential issues which are to be tackled by university communities, international engagement may make the difference between continued operation in the mainstream or relegation to academic backwaters.

\section{References}

Bolle, C.M. (1991). The evaluation abroad of diplomas in the higher education. (In Dutch). U\&H - Tijdschrift voor Wetenschappelijk Onderwijs. 38 (2): 71-88.

Rabbinge, R. and H.C. van Latesteijn. (1992). Long-term options for land use in the European Community. Agricultural Systems 40: 195-210.

Schmidt-Nielsen, B. (1993). Danish agricultural education. A small country in an open market. Pp. 13-18 in: Proceedings of the Conference 'Changes in Agriculture: a Challenge for Higher Education'. (Wageningen, April 12-15, 1992). Wageningen Agricultural University, Wageningen, the Netherlands.

Wetenschappelijke Raad voor het Regeringsbeleid (1991). Technology and government: a closer look at some sectors (in Dutch). Report to the Government nr. 39, 65 p. The Hague, the Netherlands.

Address of the authors

Department of Theoretical Production Ecology

Wageningen Agricultural University

P.O. Box 430, $6700 \mathrm{AK}$ Wageningen, The Netherlands 